\title{
PERFORMANCE OF RCC FRAME WITH SPECIAL CONFINING REINFORCEMENT ON SLOPE
}

\section{DOI:10.36909/jer.ACMM.16343}

\author{
Pradeep Sivanantham, S.Senthil Selvan* and K.S.Satyanarayanan \\ Department of Civil Engineering, SRM Institute of Science and Technology, Kattankulathur \\ 603203,Tamil Nadu, India. \\ *Corresponding Email: senthils10@srmist.edu.in..
}

\begin{abstract}
Earthquake is a natural disaster that occurs when the Earth's crust moves suddenly. Every year, hundreds of earthquakes strike various parts of the globe. According to previous research, buildings that are built on sloped terrain are the most susceptible to earthquakes. This is attributable to the different heights of the columns on the ground floor. By changing the height of the column at the base of a 2-D Conventional RCC Frame and a Special Confined RCC Frame, an experimental investigation was carried out in this study. The parameters like load verses deflection, crack width and stiffness degradation was used to draw comparison between the Conventional RCC Frame and Special confined RCC Frame under Reverse Cyclic Loading by using Push and Pull Jack. Hysteresis curve clearly shows that Special Confining reinforcement provided for the column throughout the span because of columns with varying stiffness provides additional strength and performance against lateral force by dissipating energy. The ductility of Short column improved at initial stage, meanwhile the displacement of the Special confined RCC frame with short column also improved due to ductile reinforcement-which leads to reduction in failure rate and arrest the sudden failure of the short columns in the frame as that is physically visible from the crack pattern.
\end{abstract}

Keywords: Seismic Analysis, Short Column Effect, 2D Frame, Displacement, Stiffness 


\section{INTRODUCTION}

Buildings that were planned and built according to earlier code provisions (with or without considering Earthquake Forces) have failed to meet the specifications of existing seismic code and construction practices in recent years. Earthquake disaster has always been one of the biggest natural calamities that has befallen mankind since time immemorial, bringing with it untold misery and suffering to those who are affected. Due to industrialisation and increase in population, the growth of the building has been increased on hilly areas. Buildings in hilly areas have different column heights on the ground floor, with the short columns behaving badly since a long column and a short column with the same cross section travel horizontally by the same amount during an earthquake(Cagatay, Beklen, and Mosalam 2010; Pradeep and Kunal 2017; Satyanarayanan, Anu Varshini, and Pradeep 2019) . Short columns are further stiffer than long columns thus they are wide open to seismic forces and base shear values of the buildings. These values are further high in downgrade grounds when related to buildings of constructed on typical ground (Nagarjuna 2015) as shown in Figure.1.

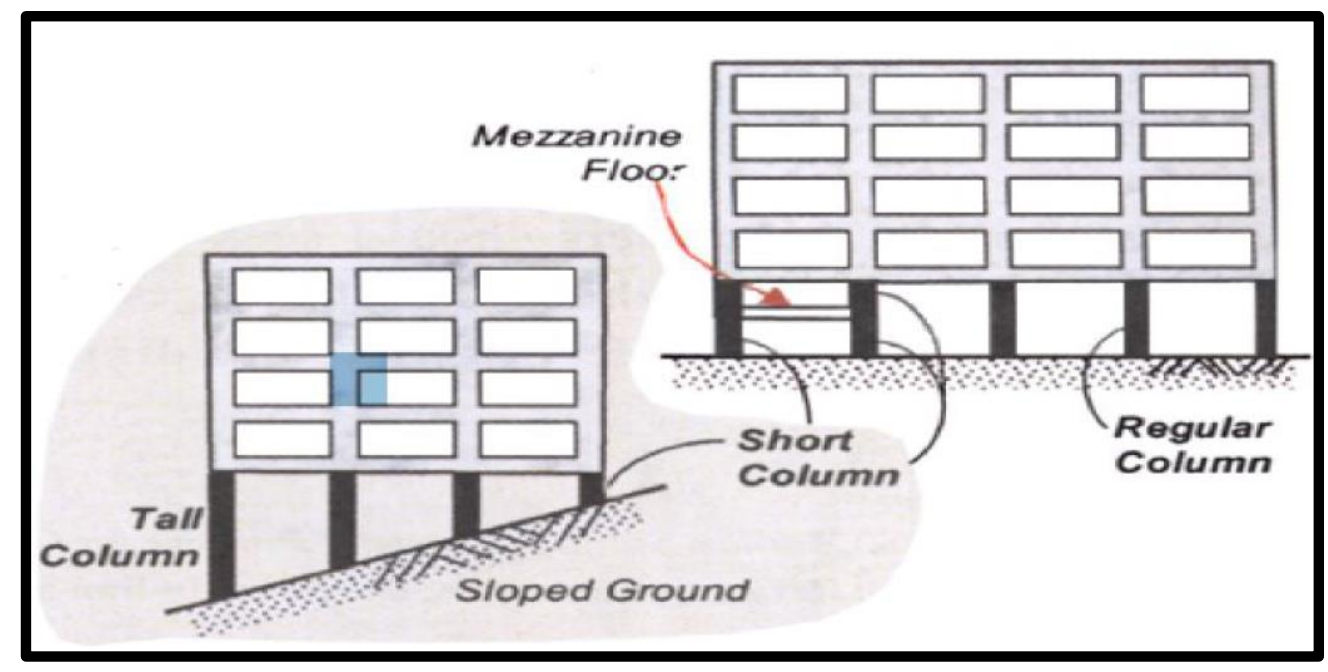

Figure.1 Buildings with Columns resting on Plane and Sloped ground

The provision of window and ventilator openings in the wall creates the short column effect. Infill walls without openings normally have a positive effect on the building's output until exposed to earth quake forces, when window and ventilator openings are given in the infill, this 
results in a partial infilling concept, which has negative earthquake effects. To scale back such impact, infill wall and shear wall were introduced conjointly and discovered that the buildings having additional range of bays will resist the seismic force(Kaltakci and Ozturk 2012). Various bracing system can be used to resist the lateral load by transferring the shear force from joint to the web member provided as the brace and later transferred to the ground through the column(Guerrero, Escobar, and Teran-Gilmore 2018). The distribution of mass and stiffness in each horizontal and vertical plane of the building determines its behavior during an earthquake; each of these factors varies in the case of mountainous buildings with irregularity and imbalance due to step back and step back set back configuration.

However, using static pushover analysis, it is essential to predict the force and deformation demands imposed on structures and their parts by extreme ground motion in order to determine the design's suitability. Two specific strategies for reinforcing concrete buildings will be considered: increasing the malleability of the concrete building and perceiving earthquake energy by plastic deformation. Various retrofitting techniques, such as the installation of new shear walls, Braces, and special confining reinforcement in compliance with (IS:13920-2016 2016), will increase the strength and stability of a house. Under reverse cyclic loading, the seismic behaviour of walls with various structural schemes and new precast member connections was investigated, and the best design scheme was found(Lu et al. 2018; Zhou et al. 2019). The majority of research is focused on increasing the strength and stability of systems, as shown by the above works. The aim of this study is to examine the efficiency of a structure with a short column effect and special confining reinforcement for the columns.

\section{EXPERIMENTAL INVESTIGATION}

The performance of the RCC Short column effect on structure under lateral loading in hilly regions was investigated experimentally. It is made up of two bare frames: one is an RCC structure with different height columns on the same storey, and the other is a special confining reinforced structure with different height columns on the same storey. This section presents the details of experimental investigation. 


\section{Material properties and specifications}

Based on previous case studies, M25 grade concrete and Fe 415 grade steel were chosen. The loading conditions are chosen based on the literature review to assess the failure load and crack pattern. The RC column's cross section was 100 x 90mm.In a standard sloped frame, longitudinal reinforcement is provided by four $6 \mathrm{~mm}$ diameter bars, and transverse reinforcement is provided by six $6 \mathrm{~mm}$ diameter bars spaced $60 \mathrm{~mm}$ centre to centre, whereas, as shown in figure 2 , transverse reinforcement of $6 \mathrm{~mm}$ diameter is given at $30 \mathrm{~mm} \mathrm{c} / \mathrm{c}$ in a special confined frame as per code IS 13929: 2016.

The cross section of RC beam is $90 \times 100 \mathrm{~mm}$. Four numbers of $6 \mathrm{~mm}$ diameter bars are provided as the longitudinal reinforcement and $6 \mathrm{~mm}$ diameter at $50 \mathrm{~mm}$ center to center web reinforcement are provided for both normal sloped frame and special confined frame, where the ductile detailing is done for shear strength consideration and variation in stiffness. At the base, a slope of 1 in 6 is given. The RC base has a length of $1300 \mathrm{~mm}$, a width of $200 \mathrm{~mm}$, and a depth that ranges from $300 \mathrm{~mm}$ at one end to $500 \mathrm{~mm}$ at the other. Reinforcement used in foundation is of $12 \mathrm{~mm}$ diameter as a main reinforcement and the stirrups are provided with $8 \mathrm{~mm}$ diameter @ $100 \mathrm{~mm} \mathrm{c/c}$. The properties of the materials used in foundations, such as concrete and steel grade, as well as reinforcement sizes and spacing, are similar to those used in column and beam reinforcement. Figure.2. shows the schematic diagram. 


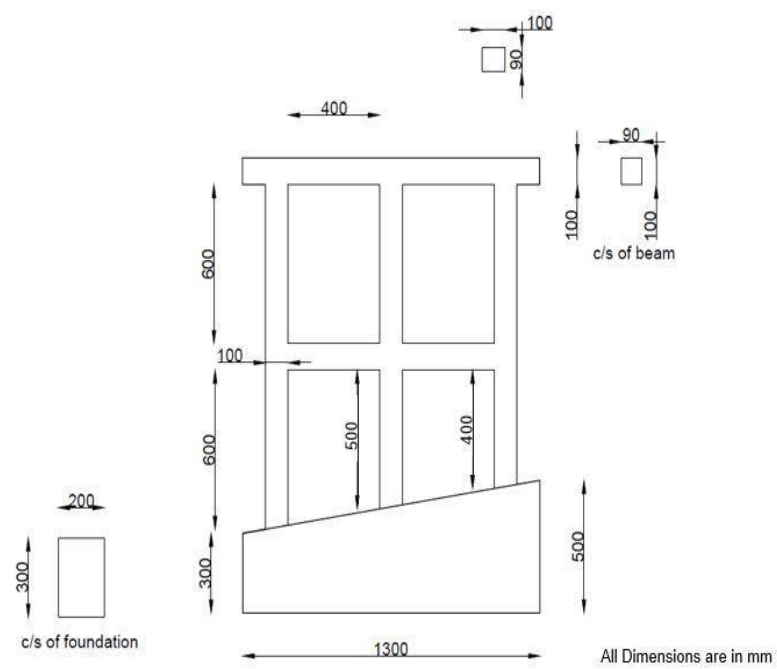

Figure.2(a).Geometry of RCC Frame with different heights

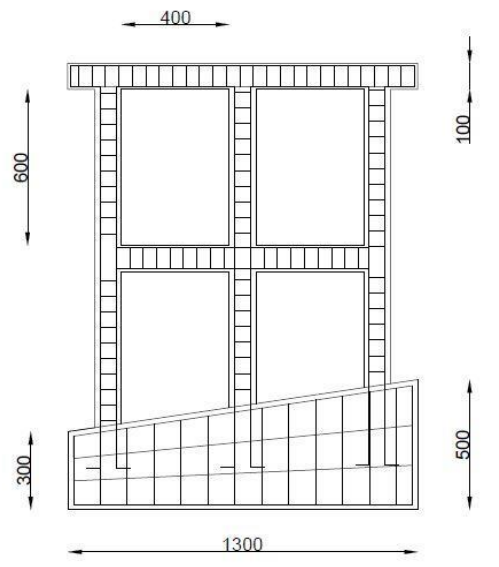

All Dimensions are in $\mathrm{mm}$
Figure.2(b).Reinforcement details of RCC Frame with different heights

\section{EXPERIMENTAL SET-UP}

With the aid of a crane, the specimen is transported to the loading frame. The specimen's base is equipped with holes for securing the base to the loading table .On both sides of the specimen; two $8 \mathrm{~mm}$ plates are bolted. The specimen is bolted and welded with cross channels for holding the specimen, so that the specimen will behave as fixed base. The frame is painted with white for better visibility and to study the crack pattern during cyclic loading.

A pumping unit with a capacity of $200 \mathrm{kN}$ is connected to a universal load cell with a capacity of $100 \mathrm{kN}$ and a load indicator on the hydraulic push and pull jack. A hinged style notch is added to the loading cell for efficient load transfer. To measure the deformations, an LVDT with a 100 $\mathrm{mm}$ push and pull capability (50 $\mathrm{mm}$ push and $50 \mathrm{~mm}$ pull) was connected with a displacement indicator along two storey nodal points. Both the regulated and special restricted reinforced frames will be mounted on the self-straining frame in the same manner as seen in Figures.3. 


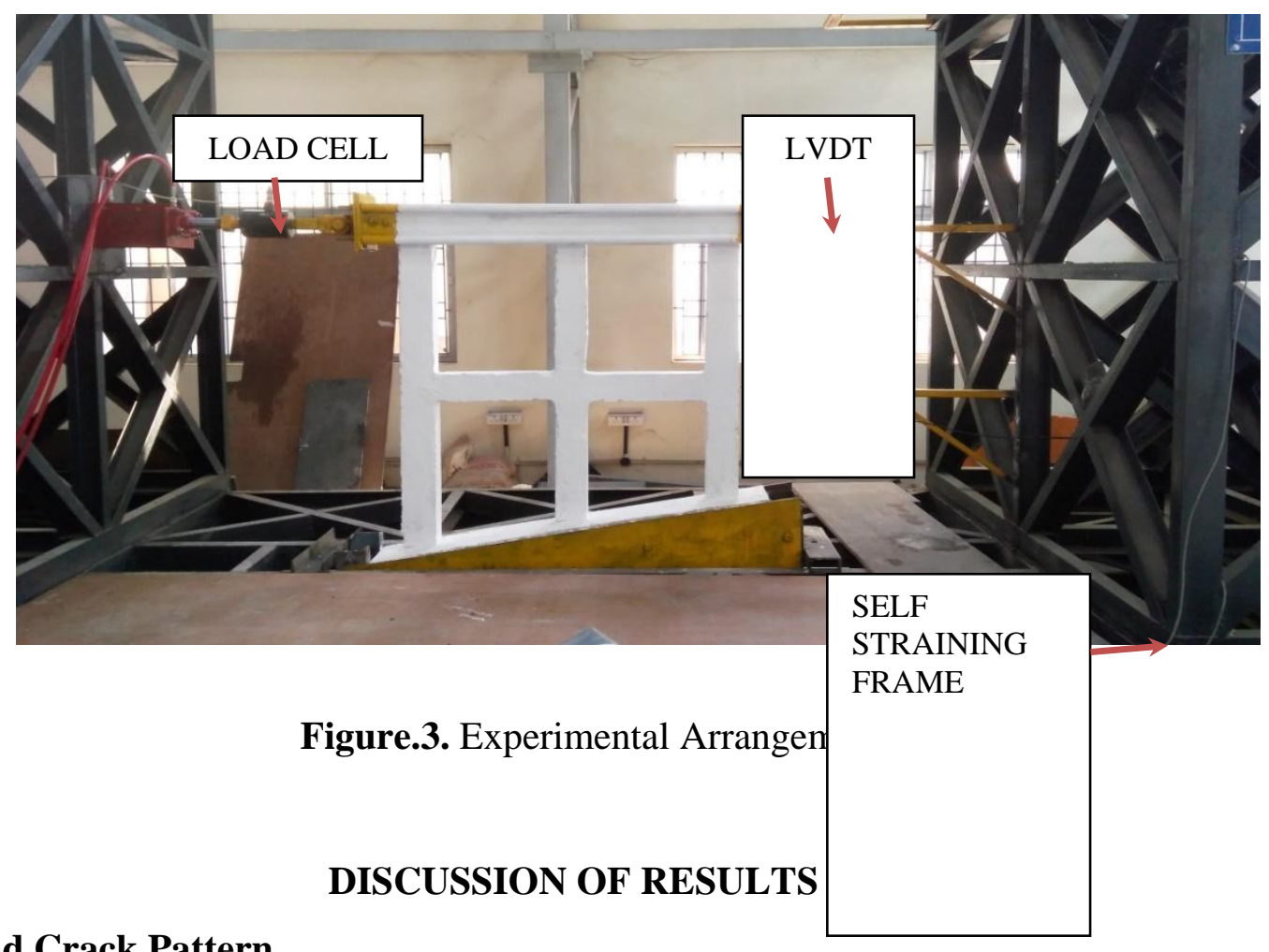

\section{Loading and Crack Pattern}

The crack observed in the specimen includes horizontal, diagonal and vertical cracks near the joints and supports on both the specimens. The first diagonal and horizontal cracks appeared on controlled specimen when the lateral load reached $8 \mathrm{kN}$, while for special confined sloped frame the development of initial crack took place at $9 \mathrm{kN}$ load level.

The Ultimate failure happens at the load of $26 \mathrm{kN}$ with the crack width of $6 \mathrm{~mm}$ for controlled frame and $32 \mathrm{kN}$ with a crack width of $3 \mathrm{~mm}$ for special confined frame near joints as shown in figure.4a and figure 4.b. The crack width observed on different location on different sized columns is mentioned in Table.1.

At introductory load, thin splits are seen close to the joints of short column as shown in figure.4.a.On further loading at ultimate load level, diagonal shear cracks developed near joints of shorter column which shows short column effect as shown in figure.4.b.

When the special confining shear reinforcement is introduced in the short column the shear cracks are not visible even in ultimate load level. Meanwhile concrete cover was seriously crushed near support of short column as shown in figure 4.c. This is due to the short column effect near the footing that attracts lot of forces attributable to increase in their stiffness. Due to the increase in stiffness, the horizontal force and bending moment conjointly increased. 


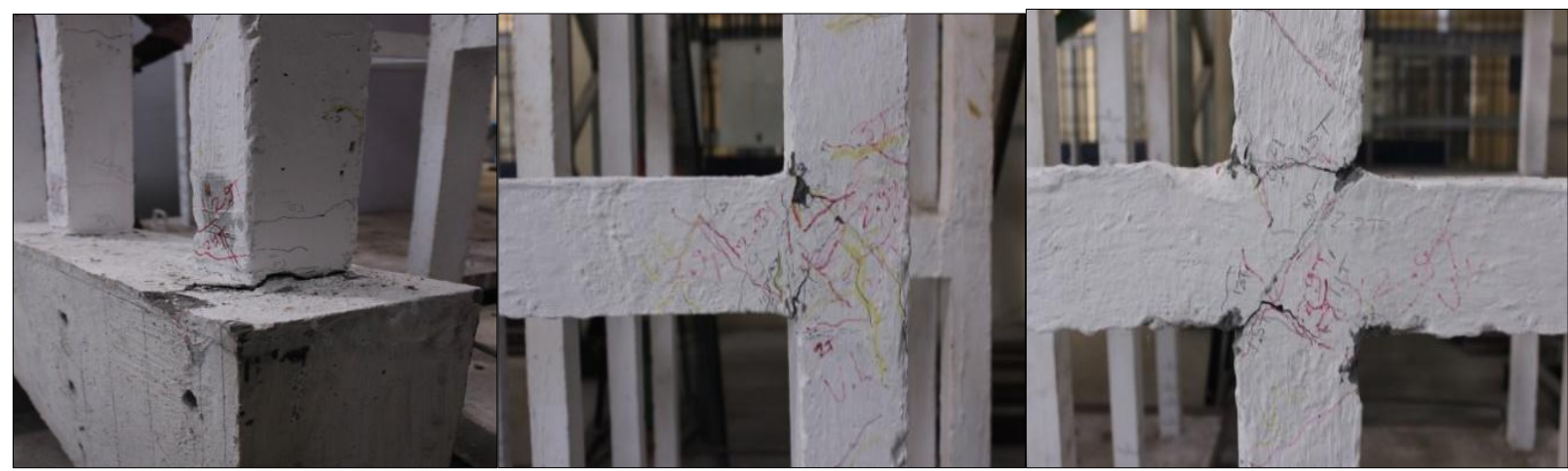

Fig.4 (a). Exterior Joints $\quad$ Fig.4(b). Interior Joints

Fig.4(c). Support

Figure.4. Failure and Crack patterns

Table1. Crack width of Different Height Columns

\begin{tabular}{|c|c|c|c|c|}
\hline \multirow{2}{*}{ S. No. } & $\begin{array}{c}\text { Description of } \\
\text { Frame }\end{array}$ & Crack & Short Column & Long Column \\
\hline \multirow{2}{*}{1} & $\begin{array}{c}\text { Conventional RCC } \\
\text { Sloped Frame }\end{array}$ & Initial & $0.1 \mathrm{~mm}$ & $0.01 \mathrm{~mm}$ \\
\cline { 3 - 5 } & Sltimate & $6 \mathrm{~mm}$ & $1.2 \mathrm{~mm}$ \\
\hline \multirow{2}{*}{2} & $\begin{array}{c}\text { Special Confining } \\
\text { Reinforcement Frame }\end{array}$ & Initial & $0.05 \mathrm{~mm}$ & $0.01 \mathrm{~mm}$ \\
\cline { 3 - 5 } & Ultimate & $3 \mathrm{~mm}$ & $0.8 \mathrm{~mm}$ \\
\hline
\end{tabular}

The lateral load applied to both the specimens at different levels either initial or ultimate is equal. The diagonal shear cracks are formed near the joints of conventional RCC Sloped frame. Meanwhile after introducing special confining reinforcement for shear strength consideration, the cracks appeared near joints are tiny. The observation of two test specimens was similar and the initial crack for conventional and special confining reinforced sloped frame is seen as hair line crack.

\section{Hysteretic behavior}

Figure.5. depicts the lateral load displacement hysteretic curve for a traditional RCC frame with short column effect and a special confining RCC frame with short column effect. The initial loading and displacement demonstrate the linear relationship. As a result, the curve's area is 
narrow and small until that point. The loading is continued until the column reaches an elastoplastic state, which causes crack extension and steel yielding. This observation shows that the hysteretic curve's slope steadily decreased while the curve's area increased.

After the lateral load is removed, the specimen exhibits residual deformation to varying degrees. At peak load, the traditional RCC's plastic deformation and damage accumulation can be seen very clearly near the joints and supports. Due to the specimen's rapid strength attenuation and the brittleness of concrete, hysteretic response was weak in the post peak load stage.

However, as compared to different longer columns in the same floor, shorter columns draw more force and all of a sudden brittle failure is observed, which is favorable for the collapse of structures during strong earthquake motion. Figure.6 shows that the frame with special confining reinforcement applied across the height of the column in accordance with ductile detailing code requirements had a greater residual deformation and a more robust hysteretic response than the conventional RCC frame with short column impact

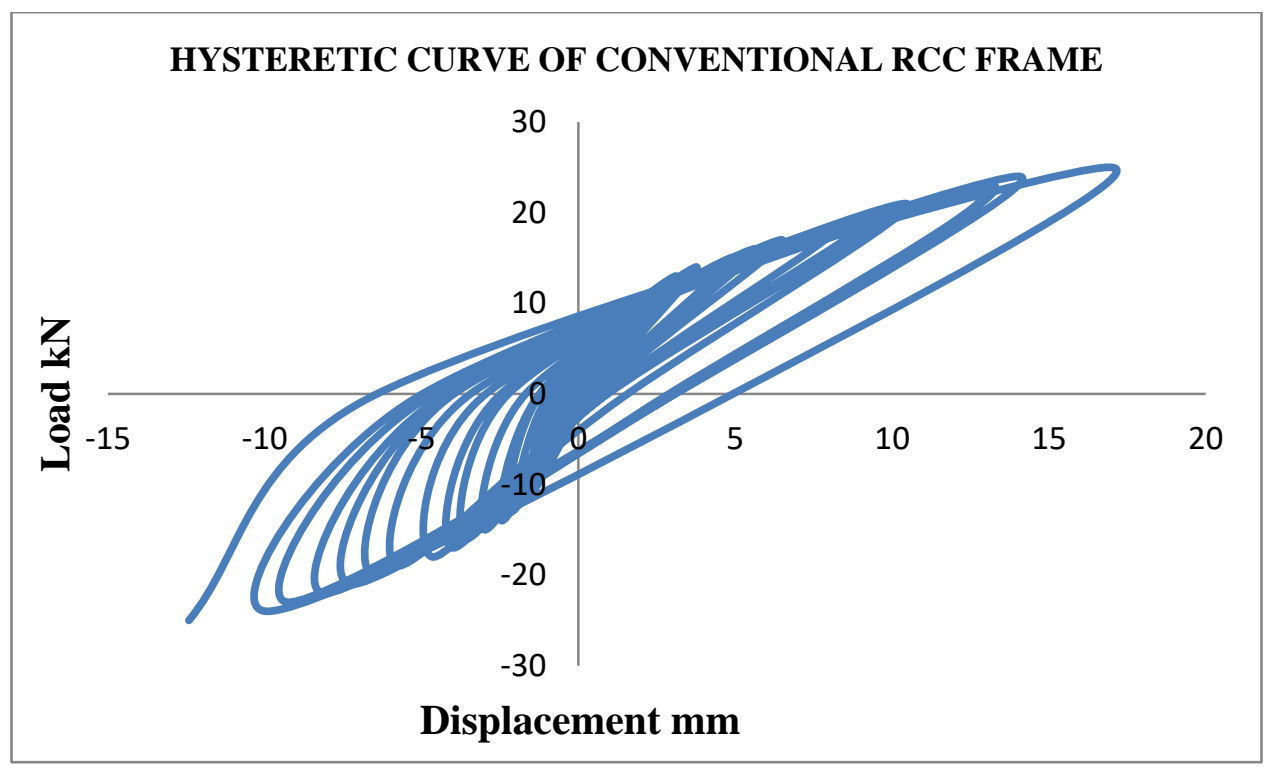

Figure.5. Conventional RCC Frame with short column effect

The stable hysteretic response of RCC frame with special confining reinforcement was achieved as because the concrete plastic deformation capacity is lesser than steel. By providing special 
confining reinforcement the area of steel reinforcement will increase which leads the increase in plastic deformation capacity and make the structure more ductile.

As compared to the conventional frame, the load bearing ability of the special confining reinforced concrete frame increased in a positive direction after the peak load, indicating that the steel used in special confining reinforcement for shear strength consideration has a plastic over strength effect. Due to the damage accumulation, the strength degeneration in negative direction is larger than positive direction for both the frame.

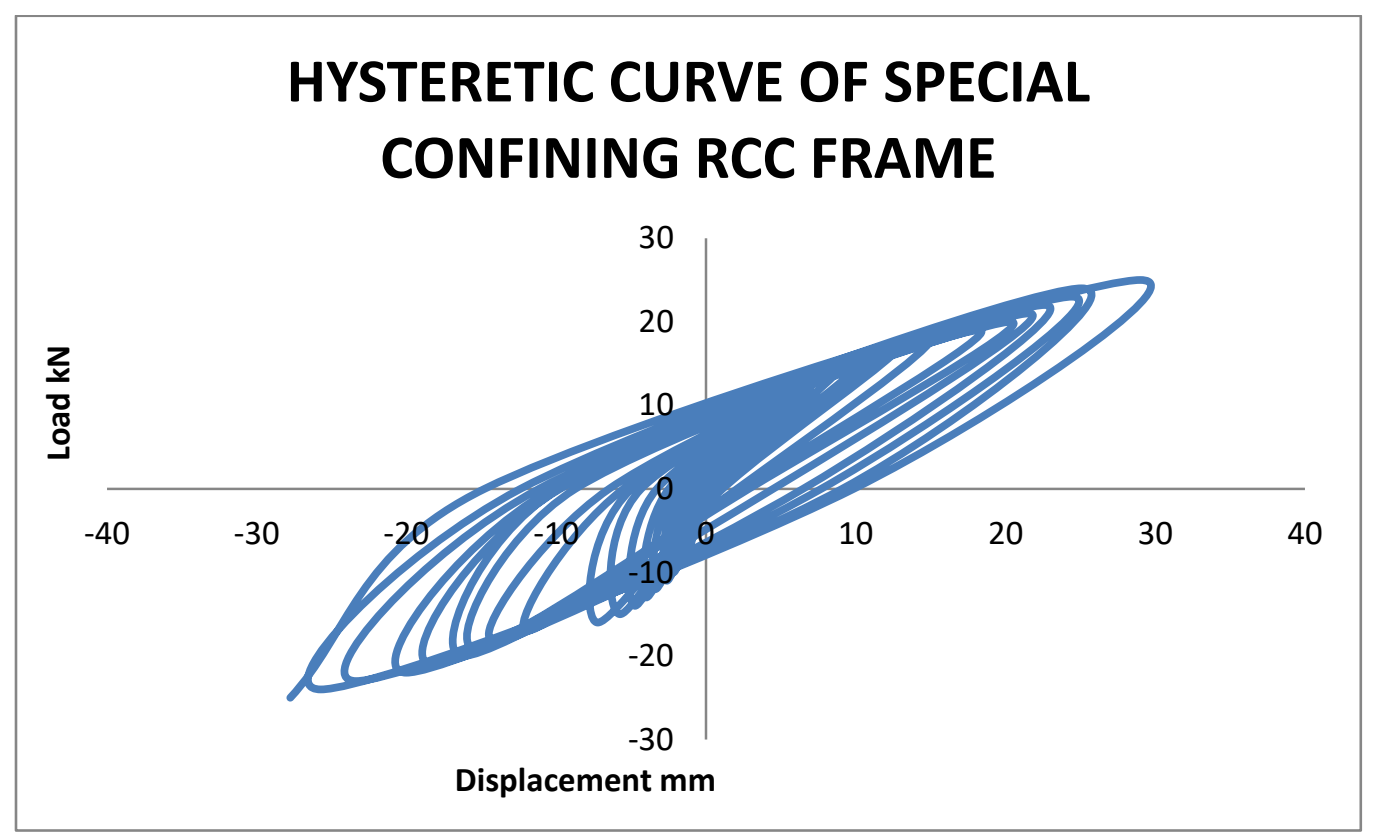

Figure.6. Special Confining RCC Frame with short column effect

\section{Stiffness degradation}

The rigidity of the frame that resists deformation in response to an applied force is known as stiffness. Stiffness degradation behavior is a significant index for evaluating the seismic response of the vertical member. With the yielding of reinforcing bars and the forming of cracks, the lateral stiffness of the specimens under cyclic loading decreases. As shown in tables 1 and 2, the secant stiffness $\mathrm{K}$ is used to analyse the stiffness deterioration of the short columns. 
From the experimental investigation it was found very clearly that the stiffness of short column in Special Confining RCC Frame is $34.70 \%$ lesser than Conventional RCC Frame at initial load. Meanwhile when it is considered for the complete frame, the stiffness of Special Confining RCC frame is $36.85 \%$ lesser than Conventional RCC Frame at initial load.

At ultimate load, the stiffness degrades at the rate of $14.58 \%$ for short column. Meanwhile the stiffness of complete Special Confining RCC Frame degrades $4.82 \%$ than that of Conventional RCC Frame. Stiffness of short column in the Special Confining RCC Frame degrades due to the provision of additional reinforcement as per IS 13920:1993 for shear strength consideration throughout the span which leads to the improvement of ductility in the column.

Table 2 Stiffness of Different Columns

\begin{tabular}{|c|c|c|c|c|c|}
\hline \multirow{2}{*}{ S. No } & \multirow{2}{*}{ Column } & \multicolumn{2}{|c|}{$\begin{array}{c}\text { Stiffness } \\
\text { at Initial Load (N/m) }\end{array}$} & \multicolumn{2}{c|}{ at Ultimate Load (N/m) } \\
\hline & & CRC & SCR & CRC & SCR \\
\hline 1 & Short Column & $1.7 \times 10^{6}$ & $1.11 \times 10^{6}$ & $1.44 \times 10^{5}$ & $1.23 \times 10^{5}$ \\
\hline 2 & Long Column & $8.33 \times 10^{5}$ & $5.26 \times 10^{5}$ & $6.12 \times 10^{4}$ & $6.43 \times 10^{4}$ \\
\hline
\end{tabular}

CRC - Conventional RCC Frame SCR-Special Confining RCC Frame

With a decrease in the stiffness deterioration rate of all columns, the lateral displacement of all columns increases. The closely spaced special confining reinforcement provided for shear strength consideration in short columns effectively maintained the tensile stress after the creation of diagonal shear cracks in short columns.

The closely spaced shear reinforcement delayed the degradation of shear strength and enhanced the lateral deformation. The frame's ductility is increased, and stiffness loss occurs at the ultimate load stage. As shear reinforcement is added, the lateral deformation is increased without collapsing. 


\section{CONCLUSION}

The experimental research and analysis is carried out, based on that the conclusion can be made as

1. Special Confining RCC short column frame exhibited stronger damage tolerance and higher crack control capacity while compared with Conventional RCC Short column frame.

2. At the failure state the displacement increased by $58 \%$ for special confined reinforcement frame while compared with the conventional RCC frame.

3. The ductile shear action of the unique confining reinforced frame is demonstrated. At the failure stage, several bond cracks appeared near special confined RCC short columns, but no crushing of covers was observed near the joints and supports. This effectively maintains the frame's integrity. While shear dominated the action of the short column. When compared to the conventional frame, the special confined RCC short column exhibits significantly better controlled hysteretic efficiency.

4. The unique confining short column's hysteretic loop had a greater area and the strength loss was slower. The efficiency of a short column was improved by using special confining reinforcement.

5. Short columns with special confining reinforcement have a high tensile property and strain power, resulting in high deformation compatibility. As a result, the deformability of the short column has greatly improved.

6. At initial load, the stiffness of the short column in the Special Confining RCC Frame is 34.70 percent lower than that of the Conventional RCC Frame. Meanwhile, the stiffness of the Special Confining RCC Frame is $36.85 \%$ less than that of the Conventional RCC Frame when taken as a whole.

With increasing lateral displacement, the rate of stiffness deterioration of all columns decreases. Following the development of diagonal shear cracks in short columns, the tightly spaced special confining reinforcement provided for shear strength consideration in short columns effectively sustained the tensile stress, enhancing lateral deformation and delaying shear strength degradation. From the above research there are certain limitations in applying load due to 
availability of instruments. If shake table is used instead of lateral cyclic loading more precious results may be derived. Meanwhile in future the studies may be carried out on provision of partial infill and Strengthening of columns with different types of wrapping.

\section{REFERENCES}

Cagatay, Ismail H., Caner Beklen, and Khalid M. Mosalam, 2010. "Investigation of Short Column Effect of RC Buildings: Failure and Prevention." Computers and Concrete 7 (6): $523-$ 32. https://doi.org/10.12989/cac.2010.7.6.523.

Guerrero, Héctor, J. Alberto Escobar, and Amador Teran-Gilmore, 2018. "Experimental Damping on Frame Structures Equipped with Buckling-Restrained Braces (BRBs) Working within Their Linear-Elastic Response." Soil Dynamics and Earthquake Engineering 106 (June 2017): 196-203. https://doi.org/10.1016/j.soildyn.2017.12.028.

IS:13920-2016, 2016. "Ductile Design and Detailing of Reinforced Concrete Structures Subjected to Seismic Forces Code of Practice." Bureau of Indian Standards, New Delhi, no. July: $1-121$.

Kaltakci, M. Yasar, and Murat Ozturk, 2012. “An Experimental Study on the Strengthening of Non-Ductile Reinforced Concrete Frames via External Shear Wall." European Journal of Environmental and Civil Engineering $16 \quad$ (1): $59-76$. https://doi.org/10.1080/19648189.2012.667672.

Lu, Cong, Bingqing Dong, Jinlong Pan, Qifeng Shan, Asad Hanif, and Wanyun Yin, 2018. "An Investigation on the Behavior of a New Connection for Precast Structures under Reverse Cyclic Loading." Engineering Structures $169 \quad$ (May): 131-40. https://doi.org/10.1016/j.engstruct.2018.05.041.

Nagarjuna, Shivakumar B. Patil, 2015. "Lateral Stability of Multistorey Building on Sloping Ground." International Research Journal of Engineering and Technology 02 (04): 56-72. www.irjet.net.

Pradeep, S., and Priyadarshi Kunal, 2017. "Analytical Study of Seismic Behaviour of RCC Frame with Short Column Effect." International Journal of Civil Engineering and Technology 8 (3): 362-72.

Satyanarayanan, K. S., R. D. Anu Varshini, and S. Pradeep, 2019. "Feasibility Studies on Proactive Disaster Prevention in Frames of Sloped Regions." Materials Today: Proceedings 14: 
315-22. https://doi.org/10.1016/j.matpr.2019.04.153.

Zhou, Xiaojie, Jinpeng Du, Quanmin Peng, and Peiqi Chen, 2019. "Hollow Block Masonry Wall Reinforced by Built-in Structural Configuration: Seismic Behavior Analysis." Soil $\begin{array}{lllll}\text { Dynamics and Earthquake } & \text { Engineering } 126 & \text { (April): } 105815 .\end{array}$ https://doi.org/10.1016/j.soildyn.2019.105815. 